\title{
Prevalence of and factors associated with head impact during falls in older adults in long-term care
}

\author{
Rebecca Schonnop BSc, Yijian Yang MD, Fabio Feldman PhD, Erin Robinson BSc, Marie Loughin MS, \\ Stephen N. Robinovitch PhD
}

\begin{abstract}
Background: Falls cause more than $60 \%$ of head injuries in older adults. Lack of objective evidence on the circumstances of these events is a barrier to prevention. We analyzed video footage to determine the frequency of and risk factors for head impact during falls in older adults in 2 long-term care facilities.
\end{abstract}

Methods: Over 39 months, we captured on video 227 falls involving 133 residents. We used a validated questionnaire to analyze the mechanisms of each fall. We then examined whether the probability for head impact was associated with upper-limb protective responses (hand impact) and fall direction.

Results: Head impact occurred in $37 \%$ of falls, usually onto a vinyl or linoleum floor. Hand impact occurred in $74 \%$ of falls but had no sig- nificant effect on the probability of head impact $(p=0.3)$. An increased probability of head impact was associated with a forward initial fall direction, compared with backward falls (odds ratio $[\mathrm{OR}] 2.7,95 \%$ confidence interval $[\mathrm{Cl}] 1.3-$ 5.9) or sideways falls (OR $2.8,95 \% \mathrm{Cl} 1.2-6.3$ ). In $36 \%$ of sideways falls, residents rotated to land backwards, which reduced the probability of head impact (OR $0.2,95 \% \mathrm{Cl} 0.04-0.8$ ).

Interpretation: Head impact was common in observed falls in older adults living in longterm care facilities, particularly in forward falls. Backward rotation during descent appeared to be protective, but hand impact was not. Attention to upper-limb strength and teaching rotational falling techniques (as in martial arts training) may reduce fall-related head injuries in older adults.
$\mathrm{F}$ alls from standing height or lower are the cause of more than $60 \%$ of hospital admissions for traumatic brain injury in adults older than 65 years. ${ }^{1-5}$ Traumatic brain injury accounts for $32 \%$ of hospital admissions and more than $50 \%$ of deaths from falls in older adults. ${ }^{1,6-8}$ Furthermore, the incidence and ageadjusted rate of fall-related traumatic brain injury is increasing, ${ }^{1,9}$ especially among people older than 80 years, among whom rates have increased threefold over the past 30 years. ${ }^{10}$ Onequarter of fall-related traumatic brain injuries in older adults occur in long-term care facilities.

The development of improved strategies to prevent fall-related traumatic brain injuries is an important but challenging task. About $60 \%$ of residents in long-term care facilities fall at least once per year, ${ }^{11}$ and falls result from complex interactions of physiologic, environmental and situational factors. ${ }^{12-16}$ Any fall from standing height has sufficient energy to cause brain injury if direct impact occurs between the head and a rigid floor surface. ${ }^{17-19}$ Improved understanding is needed of the factors that separate falls that result in head impact and injury from those that do not. ${ }^{1,10}$ Falls in young adults rarely result in head impact, owing to protective responses such as use of the upper limbs to stop the fall, trunk flexion and rotation during descent. ${ }^{20-23}$ We have limited evidence of the efficacy of protective responses to falls among older adults.

In the current study, we analyzed video footage of real-life falls among older adults to estimate the prevalence of head impact from falls, and to examine the association between head impact, and biomechanical and situational factors.

\section{Methods}

\section{Data collection}

From Apr. 20, 2007, to June, 23, 2010, we collected video footage of 227 falls experienced by 133 residents at 2 long-term care facilities: Delta View, a 312-bed facility in Delta, British Columbia, and the New Vista Care Home, a 236-bed facility in Burnaby, BC. We collected the footage from digital video cameras installed in common areas (i.e., lounges, dining areas and hallways). Delta View had 216 networked digital cameras, and the New Vista Care Home had
Competing interests: Stephen Robinovitch has received consulting fees from compliant flooring manufacturers (Satech, nora systems, Forbo,

Tarkett) and a hip protector manufacturer (Tytex). No other competing interests were declared.

This article has been peer reviewed.

Correspondence to: Stephen N. Robinovitch, stever@sfu.ca

CMAJ 2013. DOI:10.1503 /cmaj.130498 
48. Networked recorders stored video data at $640 \times 480$ pixels resolution and $4-15$ frames per second. Previously, our group analyzed this dataset to describe the causes of imbalance and activities at the time of falling..$^{24}$ In the current study, we focus on the frequency and mechanisms associated with head impact during falls. See Appendices 1-4 (available at www.cmaj.ca /lookup/suppl/doi:10.1503/cmaj.130498/-/DC1) for videos of sample falls.

As required by British Columbia's Health Act, the known occurrence of a fall triggered care personnel at the facilities to complete a fall incident report. Members of our research team reviewed incident reports to identify falls in common areas and retrieved corresponding video footage. ${ }^{24}$ In 2010 at Delta View, $45 \%$ of falls occurred in common areas; of these, $65 \%$ were captured on video. In 2010 at the New Vista Care Home, 34\% of falls occurred in common areas, and $28 \%$ of these were captured on video. ${ }^{24}$ Among falls captured on video, 55\% $(n=125)$ occurred in dining areas, $22 \%(n=51)$ occurred in hallways, $22 \%$ $(n=49)$ occurred in lounges and 1\% $(n=2)$ occurred just outside the facility, which matches trends documented on incident reports. ${ }^{24}$

Research ethics boards at Simon Fraser University and Fraser Health Authority approved this study. At the time of admission to the facility, each resident or proxy provided permission for the facility to acquire video footage in com- mon areas, for the purpose of resident safety. These data were shared as secondary data with our team. Of the 133 residents whose falls were captured on video, 37 gave consent to access their medical records.

\section{Fall analysis}

Three trained evaluators analyzed each fall captured on video with the goal of obtaining consensus on the best available answers to a structured questionnaire, ${ }^{25}$ which probed whether impact occurred to the head, whether impact occurred to the hand(s) and/or forearm(s), the initial fall direction, the landing configuration, the biomechanical cause of imbalance, and held objects at the time of falling. Tests of interrater reliability (across 2 independent teams) showed more than $80 \%$ agreement and a Cohen $\kappa$ value greater than 0.60 for 5 of the 6 items (for held objects, agreement $=73 \%$ and $\kappa=0.33) .{ }^{25}$ In tests of intrarater reliability (comparing responses $1 \mathrm{yr}$ after the initial evaluation), all 6 items exhibited more than $87 \%$ agreement and a $\kappa$ value greater than 0.67 .

\section{Statistical analysis}

We used repeated-measures logistic regression (performed using the GLIMMIX procedure of SAS version 9.2) to examine associations between the occurrence of head impact (our response variable) and the following explanatory variables: hand or forearm impact, initial fall

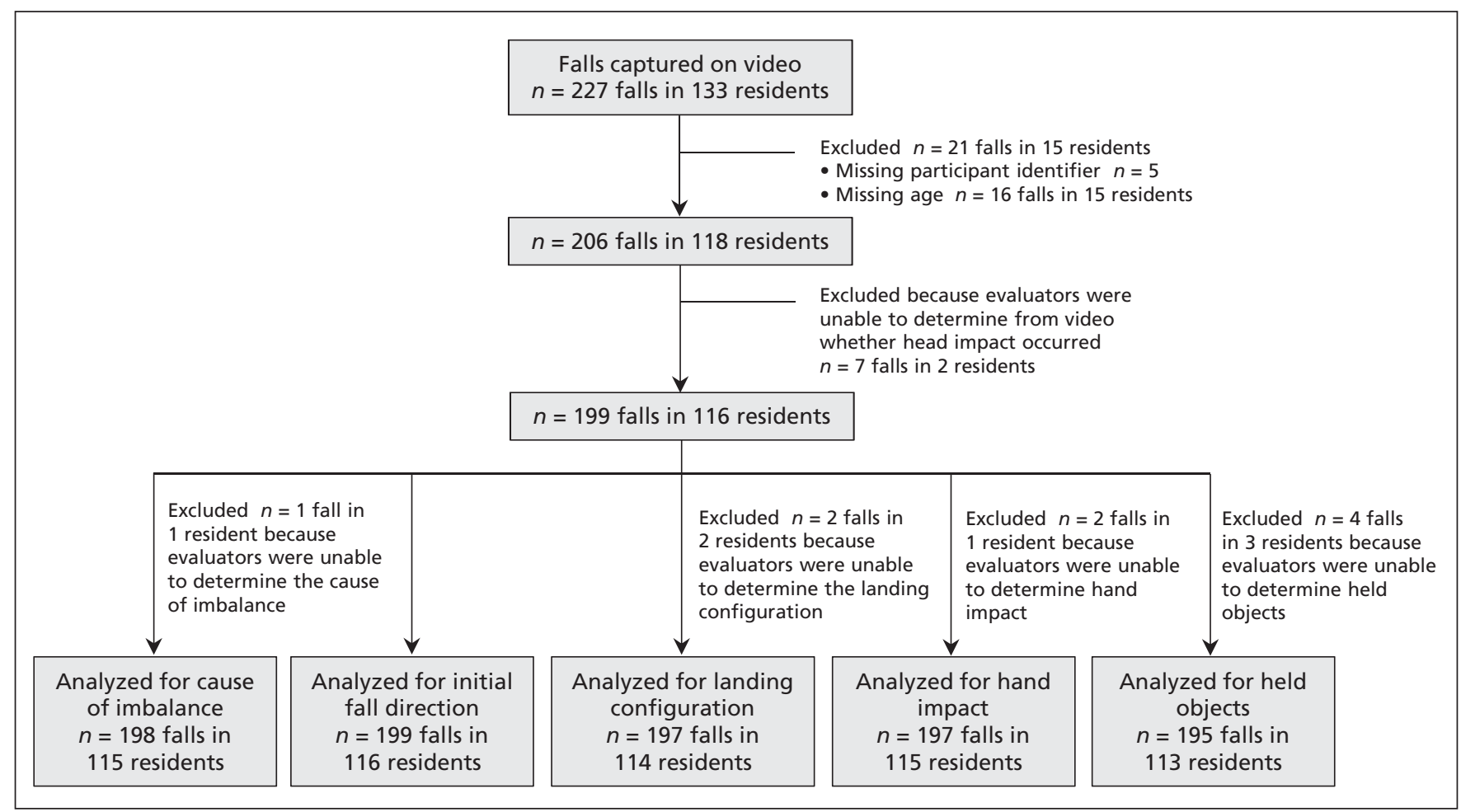

Figure 1: Flow chart showing the number of falls captured on video, reasons for exclusions, and corresponding numbers of falls and residents included in each analysis. 
direction, landing configuration, cause of imbalance and held objects. Given our modest sample size, we evaluated each explanatory variable separately, including age as a continuous covariate and sex as a dichotomous variable. We considered repeated falls by a given resident potentially correlated owing to possible underlying risk factors. Therefore, we used a repeated-measures approach to account for within-participant correlation in testing for associations. We provide estimated probabilities for head impact for all levels of each explanatory variable. For variables that exhibited a significant main effect $(p \leq 0.05)$, we report odds ratios (ORs) and corresponding 95\% confidence intervals (CIs) for pairwise comparisons. As shown in Figure 1, we omitted from the analysis 21 falls experienced by residents of unknown age $(n=16)$ or with a missing participant identifier $(n=5)$. We also omitted falls for which the team was unable to determine (e.g., because of obstruction of body parts from the camera's view) whether head impact occurred $(n=7)$ or an answer to the explanatory variable in question ( $n$ ranged from 1 to 4 ). We assumed the excluded falls occurred at random without an underlying cause, and accordingly should not have increased the bias in the results of our analysis (although they may have affected our power to detect significant effects). For falls that involved head impact, we also examined incident reports for documented injuries.

\section{Results}

Among the 133 residents whose falls were captured on video, the mean age ( \pm standard deviation) was $78 \pm 10$ years, and $52 \%$ were women. Ninety residents had 1 fall captured on video and 43 had 2 or more. Among residents who provided consent to access their health records, the characteristics of residents whose falls were captured on video were similar to those of residents who had falls that were not captured on video over a 6month period. ${ }^{24}$ The demographics and disease diagnoses in our sample were similar to those of residents $(n=3895)$ in 35 other long-term care facilities throughout the Fraser Health Authority (Table 1), with one exception. We observed a higher incidence of Alzheimer disease among residents at Delta View (38\%) and among residents with falls captured on video (49\%) than among residents in the authority-wide sample (14\%).

Among the 227 falls, head impact occurred in $37 \%$ of cases $(n=85$; Appendices 1 and 2). The head struck the ground in $64 \%$ of falls $(n=54)$, a wall in $13 \%(n=11)$ and furniture in $16 \%(n=$ 14). In $87 \%$ of falls in which the head struck the ground, the flooring was vinyl or linoleum, whereas in $13 \%$, it was carpet. Among falls involving head impact for which we had access to incident reports $(n=59)$, head injury was documented in 34\% ( $n=20)$. Among these, $45 \%(n=$ 9) were abrasions or lacerations, $30 \%(n=6)$

Table 1: Characteristics of residents at 2 long-term care facilities (New Vista Care Home and Delta View) and at long-term care facilities in the Fraser Health Authority, and study residents with falls captured on video

\begin{tabular}{|c|c|c|c|c|c|c|c|}
\hline \multirow[b]{2}{*}{ Characteristic } & \multicolumn{3}{|c|}{ Total residents } & \multicolumn{4}{|c|}{ Residents with falls captured on video $\neq$} \\
\hline & $\begin{array}{c}\text { New Vista } \\
\text { Care Home* } \\
n=180\end{array}$ & $\begin{array}{c}\text { Delta View* } \\
n=191\end{array}$ & $\begin{array}{c}\text { Fraser Health } \\
\text { Authorityt } \\
n=3895\end{array}$ & $\begin{array}{l}\text { Total } \\
n=37\end{array}$ & $\begin{array}{c}\text { Head impact } \\
\quad n=11\end{array}$ & $\begin{array}{c}\text { No head } \\
\text { impact } \\
n=19\end{array}$ & $\begin{array}{c}\text { Mix of head } \\
\text { impact and no } \\
\text { head impact } \\
n=7\end{array}$ \\
\hline \multicolumn{8}{|l|}{ Demographic } \\
\hline Age, yr, mean \pm SD & $80.8 \pm 12.4$ & $81.6 \pm 10.3$ & $83.2 \pm 11.1$ & $78.4 \pm 8.2$ & $77.7 \pm 7.5$ & $79.7 \pm 6.5$ & $75.7 \pm 13.1$ \\
\hline Female sex, no. (\%) & $120(67)$ & $116(61)$ & $2715(69.7)$ & $22(59)$ & $11(100)$ & $6(32)$ & $5(71)$ \\
\hline \multicolumn{8}{|c|}{ Disease diagnosis, no. (\%) } \\
\hline Alzheimer disease & $31(17)$ & $72(38)$ & $559(14)$ & $18(49)$ & $5 \quad(45)$ & $9(47)$ & $4(57)$ \\
\hline Diabetes & $28(16)$ & 37 (19) & $818(21)$ & $6(16)$ & $1 \quad(9)$ & $5(26)$ & 0 \\
\hline Cardiac arrhythmia & $6 \quad(3)$ & $13(7)$ & $153 \quad(4)$ & $1 \quad(3)$ & 0 & $1 \quad(5)$ & 0 \\
\hline Hypertension & $60(33)$ & $87(46)$ & $1662(43)$ & $12(32)$ & $5 \quad(45)$ & $6(32)$ & $1(14)$ \\
\hline Hypotension & $1 \quad(1)$ & 0 & $27 \quad(1)$ & 0 & 0 & 0 & 0 \\
\hline Stroke & $24(13)$ & $40(21)$ & $844(22)$ & $4(11)$ & (9) & $3(16)$ & 0 \\
\hline Parkinson disease & $4 \quad(2)$ & 11 (6) & $229 \quad(6)$ & $1 \quad(3)$ & 0 & 0 & $1(14)$ \\
\hline COPD & 15 (8) & 17 (9) & $407(10)$ & $2 \quad(5)$ & $1 \quad(9)$ & $1 \quad(5)$ & 0 \\
\hline
\end{tabular}


were hematoma and 20\% $(n=4)$ resulted in hospital visits ( 2 for nose fracture and 2 for head laceration). No concussions were noted. Among 37 residents who provided consent to access medical records, prevalences of disease diagnoses were similar among those who hit their head and those who avoided head impact (Table 1).

The estimated probability of head impact was significantly associated with initial fall direction $(p=0.009)$ and landing configuration $(p=0.01)$. Odds for head impact were greatest for falls initially directed forward and smallest for falls involving a backward landing configuration (Tables 2 and 3). The odds ratio for head impact was at least 2.7-fold larger for falls initially directed forward than falls directed backwards, sideways or straight down, and 2.5-fold larger for falls involving a forward or sideways landing configuration than a backward landing configuration (Table 3). Residents tended to rotate backwards during descent (e.g., Appendix 4), which caused a mismatch in $31 \%$ of falls between the initial fall direction and the landing configuration (Table 4). In $36 \%$ of falls initially directed sideways, residents rotated to land backwards, which was associated with reduced odds for head impact (OR 0.2, 95\% CI 0.04-0.8). In comparison, only $8 \%$ of initially sideways falls involved rotation into a forward landing configuration. In $33 \%$ of falls initially directed forward, residents

Table 2: Number of falls and estimated probabilities of head impact for the various explanatory variables

\begin{tabular}{|c|c|c|c|c|}
\hline \multirow[b]{2}{*}{ Explanatory variable* } & \multicolumn{2}{|c|}{ No. (\%) of falls } & \multirow{2}{*}{$\begin{array}{c}\text { OR for head } \\
\text { impact }(95 \% \mathrm{Cl})\end{array}$} & \multirow[b]{2}{*}{$p$ value } \\
\hline & Head impact & No head impact & & \\
\hline $\begin{array}{l}\text { Biomechanical cause } \\
\text { of imbalancet }\end{array}$ & $n=76$ & $n=122$ & & 0.6 \\
\hline Slip & $3(4)$ & $3(2)$ & $0.53(0.18-0.86)$ & \\
\hline Trip/stumble & $19(25)$ & $22(18)$ & $0.43(0.28-0.59)$ & \\
\hline Hit/bump & $8(11)$ & $15(12)$ & $0.34(0.18-0.56)$ & \\
\hline Collapse & $8(11)$ & $12(10)$ & $0.43(0.23-0.65)$ & \\
\hline Incorrect shift & $26(34)$ & $57(47)$ & $0.31(0.21-0.42)$ & \\
\hline Loss of support & $12(16)$ & $13(11)$ & $0.48(0.29-0.68)$ & \\
\hline Initial fall direction‡ & $n=77$ & $n=122$ & & 0.009 \\
\hline Forward & $30(39)$ & $21(17)$ & $0.58(0.44-0.71)$ & \\
\hline Backward & $26(34)$ & $48(39)$ & $0.33(0.23-0.45)$ & \\
\hline Sideways & $18(23)$ & $37(30)$ & $0.33(0.22-0.47)$ & \\
\hline Straight down & $3(4)$ & $16(13)$ & $0.16(0.05-0.41)$ & \\
\hline Landing configuration§ & $n=77$ & $n=120$ & & 0.01 \\
\hline Forward & $16(21)$ & $15(12)$ & $0.53(0.35-0.70)$ & \\
\hline Backward & $32(42)$ & 77 (64) & $0.29(0.21-0.38)$ & \\
\hline Sideways & $29(38)$ & $28(23)$ & $0.49(0.36-0.62)$ & \\
\hline Hand impactๆ & $n=75$ & $n=122$ & & 0.3 \\
\hline None & $16(21)$ & $32(26)$ & $0.33(0.21-0.47)$ & \\
\hline Right hand/forearm & $17(23)$ & $32(26)$ & $0.35(0.23-0.49)$ & \\
\hline Left hand/forearm & $19(25)$ & $37(30)$ & $0.34(0.22-0.47)$ & \\
\hline Both hands/forearms & $23(31)$ & $21(17)$ & $0.51(0.36-0.66)$ & \\
\hline $\begin{array}{l}\text { Held or grasped } \\
\text { objects** +t }\end{array}$ & $n=76$ & $n=119$ & & 0.7 \\
\hline No & $31(41)$ & $42(35)$ & $0.40(0.29-0.52)$ & \\
\hline Yes & $45(59)$ & $77(65)$ & $0.37(0.29-0.46)$ & \\
\hline \multicolumn{5}{|c|}{$\begin{array}{l}\text { Note: } \mathrm{Cl}=\text { confidence interval, } \mathrm{OR}=\text { odds ratio. } \\
\text { *In each model, age and sex were included as covariates. Sex tended to be significantly associated with head impact ( } p \text { values } \\
\text { ranged from } 0.03 \text { to } 0.06), \text { whereas age did not ( } p \text { values ranged from } 0.5 \text { to } 0.8) . \\
\text { tn=198 falls in } 115 \text { residents. } \\
\neq n=199 \text { falls in } 116 \text { residents. } \\
\$ n=197 \text { falls in } 114 \text { residents. } \\
\text { In } n=197 \text { falls in } 115 \text { residents. } \\
* * n=195 \text { falls in } 113 \text { residents. } \\
+\dagger \text { eld or grasped objects included, in order of frequency: chair, walker, table and coffee cup. }\end{array}$} \\
\hline
\end{tabular}


rotated to land sideways; this had no significant association with probability for head impact.

There was no significant association between the probability for head impact and impact to
1 or both hands or forearms $(p=0.3$; Table 2$)$. Impact occurred to at least 1 hand and/or forearm in $74 \%$ of all falls and in $79 \%$ of falls that involved head impact. Hand impact occurred in

Table 3: Pairwise comparison between probabilities for head impact for different initial fall directions and landing configurations*

\begin{tabular}{|c|c|c|c|}
\hline Levels compared & & $\begin{array}{l}\text { OR for head impact } \\
\qquad(95 \% \mathrm{Cl})\end{array}$ & $p$ value $t$ \\
\hline Initial fall direction A & \multicolumn{3}{|l|}{ Initial fall direction B } \\
\hline Forward & Backward & $2.7 \quad(1.3-5.9)$ & 0.01 \\
\hline Forward & Sideways & $2.8 \quad(1.2-6.3)$ & 0.02 \\
\hline Forward & Straight down & $7.2(1.8-29.0)$ & 0.006 \\
\hline Backward & Sideways & $1.0 \quad(0.5-2.2)$ & $>0.9$ \\
\hline Backward & Straight down & $2.6 \quad(0.7-10.2)$ & 0.2 \\
\hline Sideways & Straight down & $2.6 \quad(0.6-10.6)$ & 0.2 \\
\hline Landing direction $\mathrm{A}$ & \multicolumn{3}{|l|}{ Landing direction B } \\
\hline Forward & Backward & $2.7 \quad(1.2-6.4)$ & 0.02 \\
\hline Forward & Sideways & $1.2(0.5-2.9)$ & 0.8 \\
\hline Sideways & Backward & $2.5 \quad(1.2-4.8)$ & 0.01 \\
\hline \multicolumn{4}{|c|}{$\begin{array}{l}\text { Note: } \mathrm{Cl}=\text { confidence interval, } \mathrm{OR}=\text { odds ratio. } \\
\text { *Pairwise comparisons between levels of the additional explanatory variables shown in Table } 2 \text { (biomechanical cause of } \\
\text { imbalance, hand impact and held objects) were not significant }(p \geq 0.09) \text {. } \\
t p \text { values are not adjusted for the } 9 \text { comparisons. }\end{array}$} \\
\hline
\end{tabular}

Table 4: Combinations of initial fall direction and landing configuration, with corresponding number of falls and probabilities for head impact

\begin{tabular}{|c|c|c|c|c|}
\hline \multirow{2}{*}{$\begin{array}{l}\text { Initial fall direction; } \\
\text { landing configuration }\end{array}$} & \multicolumn{3}{|c|}{ No. (\%) of falls } & \multirow[b]{2}{*}{ ORt $(95 \% \mathrm{Cl})$} \\
\hline & Total & Head impact* & No head impact* & \\
\hline \multicolumn{5}{|l|}{ Forward, $n=60$} \\
\hline Forward & 32 (53) & $19 \quad(59)$ & $13(41)$ & NA \\
\hline Backward & 8 (13) & $(50)$ & $4(50)$ & $0.7(0.1-3.6)$ \\
\hline Sideways & $20 \quad(33)$ & $12(60)$ & $8(40)$ & $1.1(0.3-3.4)$ \\
\hline \multicolumn{5}{|l|}{ Backward, $n=79$} \\
\hline Forward & 0 & 0 & 0 & $-\ddagger$ \\
\hline Backward & $71 \quad(90)$ & $24 \quad(34)$ & $47 \quad(66)$ & NA \\
\hline Sideways & $8 \quad(10)$ & $3 \quad(37)$ & $5 \quad(63)$ & $1.1(0.2-5.6)$ \\
\hline \multicolumn{5}{|l|}{ Sideways, $n=59$} \\
\hline Forward & $5 \quad(8)$ & $1 \quad(20)$ & $4 \quad(80)$ & $0.3(0.03-3.0)$ \\
\hline Backward & $21 \quad(36)$ & 3 (14) & $18(86)$ & $0.2(0.04-0.8)$ \\
\hline Sideways & $33 \quad(56)$ & $16 \quad(49)$ & $17 \quad(51)$ & NA \\
\hline \multicolumn{5}{|l|}{ Straight down, $n=19$} \\
\hline Forward & 0 & 0 & 0 & $-\S$ \\
\hline Backward & $15 \quad(79)$ & 2 (13) & $13(87)$ & $-\S$ \\
\hline Sideways & $4 \quad(21)$ & $1 \quad(25)$ & $3(75)$ & $-\S$ \\
\hline \multicolumn{5}{|c|}{$\begin{array}{l}\text { Note: } \mathrm{Cl}=\text { confidence interval, } \mathrm{NA}=\text { not applicable, } \mathrm{OR}=\text { odds ratio. } \\
\text { *Percentages in this column are based on row totals. } \\
\text { tOdds ratios and } 95 \% \text { Cls show the effect on probability for head impact of changes in fall direction versus landing in the same } \\
\text { configuration as the initial fall direction. } \\
\text { †We were unable to calculate an OR for backward to forward (owing to } 0 \text { cases). } \\
\text { \$We were unable to calculate ORs for falls initially directed straight down, because a straight down landing configuration was } \\
\text { not included as an option in our questionnaire. }\end{array}$} \\
\hline
\end{tabular}


97\% of falls that involved head impact and an initially forward fall direction. The corresponding percentages were $56 \%$ for backward falls, $84 \%$ for sideways falls and $67 \%$ for falls directed straight down. Moreover, there was no significant association between the probability for head impact and held objects at the time of falling $(p=0.7)$ or biomechanical cause of imbalance $(p=0.6$; Table 2).

In unadjusted analyses, the estimated probability of head impact was not associated with age $(p=0.9)$, but reached borderline significance with sex $(p=0.09$; men: estimated probability $0.32,95 \%$ CI $0.24-0.42$; women: $0.44,95 \%$ CI $0.35-0.53)$. As covariates in our models, sex tended to associate significantly with head impact (with women having a greater likelihood; $p$ values ranging from 0.03 to 0.06 ), whereas age did not ( $p$ values ranging from 0.5 to 0.8 ).

\section{Interpretation}

Based on analysis of video footage of real-life falls, this study provides new evidence on the frequency and factors associated with head impact during falls among older adults in common areas of long-term care facilities. We found that head impact occurred in $37 \%$ of falls. By any measure, this is an alarmingly high prevalence.

Recent studies have documented a rapid increase among older adults in age-adjusted rates for fall-related head injuries, especially in the long-term care environment. ${ }^{1,9,10}$ The reasons for these trends are poorly understood. Proposed mechanisms include the increased prevalence of chronic conditions and polypharmacy, which affect the frequency of falls and risk of head impact during a fall, and the increased use of anticoagulants, which affects risk of intracranial hemorrhage following head impact. ${ }^{1,910}$

We found that use of the upper limbs to stop the fall, a common behaviour in residents included in this study, were ineffective in preventing head impact. Previous studies have shown that hand impact is protective against head impact among young people ${ }^{20,21}$ and reduces risk of injury during falls among communitydwelling older adults. ${ }^{12,26}$ However, stopping a fall with the upper limbs is demanding in terms of speed, coordination and strength to prevent arm collapse. ${ }^{22,23,27}$ It also depends on the intactness of neurologic systems to detect falls and to rapidly select a motor program (for hand placement and energy absorption) appropriate to a given situation. Our participants displayed a tendency to move their arms into a protective position (hand impact occurred in $74 \%$ of falls), which signals persistence in the generation and execution of upper-limb protective responses.
Although we cannot identify why hand impact was generally ineffective in halting downward movement and preventing head impact, likely causes include ineffective arm placement; nonoptimal muscle tone or muscle activation at impact; ${ }^{28}$ and insufficient strength in upper-limb, neck and trunk muscles, ${ }^{22,23}$ which is amenable to improvement through resistance training.

A commonly employed behaviour among our participants was rotating backwards during descent, which reduced the odds for head impact. This behaviour calls into question the notion of a single fall direction, as employed in most clinical studies of falls. ${ }^{26,29}$ Laboratory studies have documented the ability of young adults to volitionally alter their fall direction by rotating forward or backwards during descent ${ }^{30}$ but have not evaluated this behaviour during real-life falls in older adults. Our participants displayed a distinct preference (in falls initially directed sideways) for backward as opposed to forward rotation during descent, which reduced the odds for head impact. This behaviour mimics the falling strategies used in martial arts training, and the reduced odds for head impact supports the potential benefit of such training programs for older adults. ${ }^{31}$

\section{Limitations}

We analyzed falls captured on video to determine the frequency of and factors predisposing to head impact, a primary determinant of risk of head injury. ${ }^{8}$ However, we did not include head injuries in our analysis or measures of impact severity (based, for example, on head impact configuration and velocity).

Because we analyzed falls in common areas of long-term care facilities, our results may not reflect the range of mechanisms of falls in bedrooms and bathrooms (which pose a different environmental and situational context).

We did not include physiologic factors in our models, given the small portion of participants who provided us with access to medicals records and the large number of risk factors to consider (e.g., physical and cognitive function, disease diagnoses and use of medications). Larger cohort studies or case studies that link video footage of falls to comorbidities, medication use and functional status may reveal further layers of causality and inform patient-based approaches to prevention of fall-related injuries.

\section{Conclusion}

Head impact was common in observed falls in older adults living in long-term care facilities, particularly in forward falls. Backward rotation during descent appeared to be protective, but hand impact was not. 
Our study carries 3 implications for improvements in the prevention and treatment of fallrelated head injuries in older adults. First, our results raise questions about the potential underdiagnosis and need for improved procedures for detecting fall-related brain injuries in the longterm care environment. In our study, more than 1 in 3 falls resulted in head impact, most often onto a rigid (vinyl or linoleum) floor. In a third of cases, there was reported bruising, swelling or laceration, but no concussions were documented on fall incident reports. This may reflect the challenges in long-term care of separating (with current tools) the cognitive effects of head injury from baseline dementia, ${ }^{32}$ and the need to consider computed tomographic scanning to detect brain injuries for any fall-related hospital admission from long-term care. These are important questions for future research.

Second, our results help to inform the design of improved screening for risk factors and programs for the prevention of head injuries from falls. Upper-limb strength (and movement speed) should be assessed carefully in the older adult who presents with a fall-related injury, and adults should be encouraged across their lifespan to engage in exercises to strengthen upper limbs to improve their ability to stop a fall..$^{23}$ As previously mentioned, future research should also examine the potential benefit for older adults of carefully designed training based on martial arts falling techniques. ${ }^{31}$

In the long-term care setting, the high rate of cognitive and physical impairment among residents creates challenges for widespread implementation of exercise programs, and attention should focus additionally on the design of safer environments. In previous studies, appropriately tuned compliant flooring attenuated impact forces to the head by $80 \%$ (and to the hip by $40 \%$ ), without impairing the mobility and balance of older women. ${ }^{33,34}$ Our results support the need for ongoing efforts to examine the clinical efficacy and cost-effectiveness of this intervention. ${ }^{35,36}$

\section{References}

1. Harvey LA, Close JC. Traumatic brain injury in older adults: characteristics, causes and consequences. Injury 2012;43:1821-6.

2. Bouras T, Stranjalis G, Korfias S, et al. Head injury mortality in a geriatric population: differentiating an "edge" age group with better potential for benefit than older poor-prognosis patients. J Neurotrauma 2007;24:1355-61.

3. Ingebrigtsen T, Mortensen K, Romner B. The epidemiology of hospital-referred head injury in northern Norway. Neuroepidemiology 1998; 17:139-46

4. Kannus P, Palvanen M, Niemi S, et al. Increasing number and incidence of fall-induced severe head injuries in older adults: nationwide statistics in Finland in 1970-1995 and prediction for the future. Am J Epidemiol 1999;149:143-50.

5. Tiret L, Garros B, Maurette P, et al. Incidence, causes and severity of injuries in Aquitaine, France: a community-based study of hospital admissions and deaths. Am J Public Health 1989;79: 316-21.
6. Saari P, Heikkinen E, Sakari-Rantala R, et al. Fall-related injuries among initially 75- and 80-year old people during a 10year follow-up. Arch Gerontol Geriatr 2007;45:207-15.

7. Thompson HJ, McCormick WC, Kagan SH. Traumatic brain injury in older adults: epidemiology, outcomes, and future implications. J Am Geriatr Soc 2006;54:1590-5.

8. Thomas KE, Stevens JA, Sarmiento K, et al. Fall-related traumatic brain injury deaths and hospitalizations among older adults — United States, 2005. J Safety Res 2008;39:269-72.

9. Watson WL, Mitchell R. Conflicting trends in fall-related injury hospitalisations among older people: variations by injury type. Osteoporos Int 2011;22:2623-31.

10. Korhonen N, Niemi S, Parkkari J, et al. Incidence of fall-related traumatic brain injuries among older Finnish adults between 1970 and 2011. JAMA 2013;309:1891-2.

11. Rubenstein LZ, Josephson KR, Robbins AS. Falls in the nursing home. Ann Intern Med 1994;121:442-51.

12. Nevitt MC, Cummings SR, Hudes ES. Risk factors for injurious falls: a prospective study. J Gerontol 1991;46:M164-70.

13. Tinetti ME. Factors associated with serious injury during falls by ambulatory nursing home residents. J Am Geriatr Soc 1987;35: 644-8.

14. Tinetti ME, Doucette J, Claus E, et al. Risk factors for serious injury during falls by older persons in the community. $J \mathrm{Am}$ Geriatr Soc 1995;43:1214-21.

15. Wild D, Nayak US, Isaacs B. Prognosis of falls in old people at home. J Epidemiol Community Health 1981;35:200-4.

16. Wild D, Nayak US, Isaacs B. How dangerous are falls in old people at home? Br Med J (Clin Res Ed) 1981;282:266-8.

17. Bowers B, Lloyd J, Lee W, et al. Biomechanical evaluation of injury severity associated with patient falls from bed. Rehabil Nurs 2008;33:253-9.

18. Raymond DE, Catena RD, Vaughan TR. Biomechanics and injury risk assessment of falls onto protective floor mats. Rehabil Nurs 2011;36:248-54.

19. Hayes WC, Myers ER, Robinovitch SN, et al. Etiology and prevention of age-related hip fractures. Bone 1996;18(Suppl):77S-86S

20. Feldman F, Robinovitch SN. Reducing hip fracture risk during sideways falls: evidence in young adults of the protective effects of impact to the hands and stepping. J Biomech 2007;40: 2612-8.

21. Hsiao ET, Robinovitch SN. Common protective movements govern unexpected falls from standing height. J Biomech 1998; $31: 1-9$.

22. DeGoede KM, Ashton-Miller JA. Biomechanical simulations of forward fall arrests: effects of upper extremity arrest strategy, gender and aging-related declines in muscle strength. $J$ Biomech 2003;36:413-20.

23. Sran MM, Stotz PJ, Normandin SC, et al. Age differences in energy absorption in the upper extremity during a descent movement: implications for arresting a fall. J Gerontol A Biol Sci Med Sci 2010; 65:312-7.

24. Robinovitch SN, Feldman F, Yang Y, et al. Video capture of the circumstances of falls in elderly people residing in long-term care: an observational study. Lancet 2013;381:47-54.

25. Yang Y, Schonnop R, Feldman F, et al. Development and validation of a questionnaire for analyzing real-life falls in long-term care captured on video. BMC Geriatr 2013;13:40.

26. Nevitt MC, Cummings SR. Type of fall and risk of hip and wrist fractures: the study of osteoporotic fractures. The Study of Osteoporotic Fractures Research Group. J Am Geriatr Soc 1993; 41:1226-34.

27. Robinovitch SN, Normandin SC, Stotz P, et al. Time requirement for young and elderly women to move into a position for breaking a fall with outstretched hands. J Gerontol A Biol Sci Med Sci 2005;60:1553-7.

28. Dietz V, Noth J. Pre-innervation and stretch responses of triceps bracchii in man falling with and without visual control. Brain Res 1978;142:576-9.

29. Greenspan SL, Myers ER, Kiel DP, et al. Fall direction, bone mineral density, and function: risk factors for hip fracture in frail nursing home elderly. Am J Med 1998;104:539-45.

30. Robinovitch SN, Inkster L, Maurer J, et al. Strategies for avoiding hip impact during sideways falls. J Bone Miner Res 2003;18: 1267-73.

31. Weerdesteyn V, Groen BE, van Swigchem R, et al. Martial arts fall techniques reduce hip impact forces in naive subjects after a brief period of training. J Electromyogr Kinesiol 2008;18:235-42.

32. Karon SL, Lazarus JA, Holman L. Challenges and approaches to the identification of traumatic brain injury among nursing home residents. J Head Trauma Rehabil 2007;22:350-9.

33. Wright $\mathrm{AD}$, Laing $\mathrm{AC}$. The influence of headform orientation and flooring systems on impact dynamics during simulated fallrelated head impacts. Med Eng Phys 2012;34:1071-8. 
34. Laing AC, Robinovitch SN. Low stiffness floors can attenuate fall-related femoral impact forces by up to $50 \%$ without substantially impairing balance in older women. Accid Anal Prev 2009; 41:642-50.

35. Drahota A, Gal D, Windsor J, et al. Pilot cluster randomized controlled trial of flooring to reduce injuries from falls in elderly care units: study protocol. Inj prev 2011;17:e7.

36. Mackey DM, Feldman F, Laing AC,et al. Flooring for Injury Prevention Trial (FLIP). ClinicalTrials.gov Identifier: NCT01618786. June 2012 .

Affiliations: Injury Prevention and Mobility Laboratory, Department of Biomedical Physiology and Kinesiology (Schonnop, Yang, Feldman, Robinson, Robinovitch), Simon Fraser University, Burnaby, BC; School of Engineering Science (Robinovitch), Simon Fraser University, Burnaby, BC; Older Adult Program (Feldman), Fraser Health Authority, Surrey, BC; and Department of Statistics and Actuarial Science (Loughin), Simon Fraser University, Burnaby, BC. All authors are members of the Technology for Injury Prevention in Seniors (TIPS) program at Simon Fraser University.

Contributors: Rebecca Schonnop and Yijian Yang were joint primary authors. The study was conceived by Rebecca Schonnop, Yijian Yang, Fabio Feldman, Erin Robinson and Stephen Robinovitch, and supervised by Stephen Robinovitch. These same 5 authors contributed to data acquisition and, with statistician Marie Loughin, to data analysis and interpretation. The manuscript was drafted by Rebecca Schonnop, Yijian Yang, Erin Robinson, Marie Loughin and Stephen Robinovitch, and revised by Fabio Feldman. All authors gave final approval of the version submitted for publication. Rebecca Schonnop, Yijian Yang and Stephen Robinovitch had full access to all of the data in the study and take responsibility for the integrity of the data and the accuracy of the data analysis.

Funding: This study was funded by team grants from the Canadian Institutes of Health Research (grant nos. AMG100487 and TIR-103945). Stephen Robinovitch also received support from the Canada Research Chairs Program, and Rebecca Schonnop received fellowship support from the Canadian Institutes of Health Research. The funding agencies had no direct role in the design and conduct of this study; the collection, management, analysis or interpretation of the data; or the preparation, review or approval of the manuscript.

Acknowledgments: The authors thank staff and residents of Delta View and the New Vista Care Home for their partnership in this study. They are especially grateful to the individuals who provided permission to have their videos included with this paper.

Some results in this manuscript were presented in abstract form at the joint congress of the International Society for Posture and Gait Research, and Gait and Mental Function, June 24-28, 2012, Trondheim, Norway; the meeting of the Rehabilitation Engineering and Assistive Technology Society of North America, June 5-8, 2011, Toronto, Ont.; and the International Society for Gerontechnology 7 th World Conference, May 27-30, 2010, Vancouver, BC.

See the following videos online:
Appendices 1-4: Examples of falls
captured on video
www.cmaj.ca/lookup/suppl
/doi:10.1503/cmaj.130498/-/DC1

